\title{
Accuracy Comparison between GPS Real Time Kinematic (RTK) Method and Total Station to Determine the Coordinate of an Area
}

\author{
Ispen Safrel $^{1, \text { a) }}$, Eko Nugroho Julianto ${ }^{1}$, and Nur Qudus Usman ${ }^{1}$ \\ ${ }^{1}$ Civil Engineering Department, Universitas Negeri Semarang \\ a) Corresponding author: Ispen.Safrel@yahoo.com
}

\begin{abstract}
Survey with GPS Real Time Kinematic (RTK) has the advantage of being faster and easier than the total station, but on the other hand the accuracy of GPS Real Time Kinematic (RTK) is considered lacking. This study was to determine the comparison of accuracy and efficiency of measuring land parcels using a total station and GPS Real Time Kinematic (RTK) method. The research location is at the Universitas Negeri Semarang campus by selecting areas that are open or unobstructed to satellites and congested areas or which have many obstacles to satellites. The results of this study indicate that for open areas, measurement with GPS Real Time Kinematic (RTK) method reaches a horizontal accuracy of $0.040 \mathrm{~m}$ with a time of 16 minutes 16 seconds. While the measurement using a horizontal accuracy of 0.00 Total Station with a length of time of 26 minutes 47 seconds. For areas that are densely measured, GPS Real Time Kinematic (RTK) achieves horizontal accuracy of $10.053 \mathrm{~m}$ with a length of time of 39 minutes 27 seconds. While the measurement using a precision horizontal Total Station 0.00 with the length of time 25 minutes 41 seconds.
\end{abstract}

\section{INTRODUCTION}

GPS Real Time Kinematic (RTK) is a part of topographic surveys. In GPS RTK, GPS signals are transmitted in real time from a base receiver at a known position to another rover receivers. [1] for horizontal positioning suggests that the criteria that are not fulfilled due to the polygon network used in the study has an unfavorable form ie some of the sides are too short. This condition resulted in the measurement of the distance with Total Station to be inaccurate. Whereas in observations with GPS the RTK method also provides a form of network that is not good, most likely due to the short distance between points of the polygon. [2] The use of Real Time Kinematic GPS receiver RTK obtained the accuracy of the average point position measurement results using GPS RTK compared to using ETS (Electronic Total Station) is $0.214 \mathrm{~m}$ so that it can be applied to map scale 1: 500 . For open areas, measuring the land area using GPS RTK takes two times faster than ETS, but RTK GPS is less accurate when in a closed measurement area.

The use of GPS receivers in the Real Time Kinematic (RTK) method for point positioning is now widely used. This is because the use of this method makes it possible to get a precise point position with a relatively short time. On that basis, then in this study, there will be development of a comparative study experiment on the use of GPS RTK method with Total Station for determining land parcels. The Global Positioning System (GPS) is a navigation and positioning system using satellites developed and managed by the United States Department of Defense. GPS can provide information about the position, speed and time anywhere on earth at any time, with the accuracy of positioning in millimeters up to meters. Its reach capabilities cover the whole world and can be used by many people at any time at the same time. [3] The basic principle of positioning with GPS is the backward intersection with the distance measurement to the satellite as shown figure 1. 


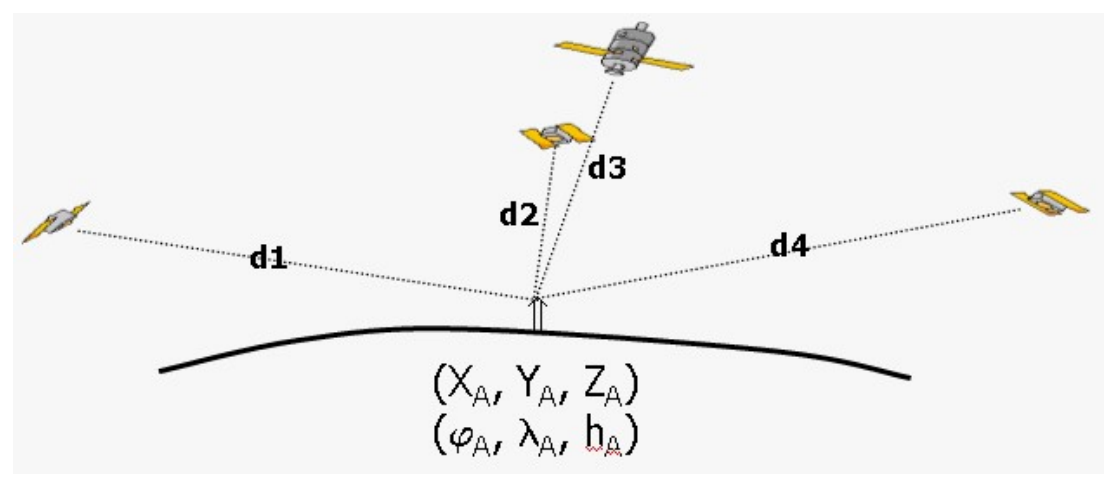

FIGURE 1. Research location points [3]

To be able to implement the principle of positioning above, GPS is managed in a GPS system which consists of 3 main parts, namely the space, the controller and the user.

The accuracy of the position obtained by GPS observation in general will depend on four factors: the positioning method used, the geometry and distribution of the observed satellites, the accuracy of the data used, and the data processing method applied. Each of these factors has several parameters that affect the accuracy of the position to be obtained from GPS.

In the journey from the satellite to reach the antenna on the earth's surface, the GPS signal will be affected by several errors and biases. GPS errors and biases can basically be grouped on errors and biases related to:

a. Satellites, such as ephemeris errors, satellite clocks, and selective availability (SA)

b. Propagation medium, such as the ionospheric bias and tropospheric bias.

c. GPS receiver, such as receiver clock errors, errors related to the antenna, and noise.

d. Observation data, such as ambiguity phase and cycle slips.

e. The environment around the GPS receiver, such as multipath.

Real-Time Kinematic System (RTK) is an acronym that is commonly used for differential real-time positioning systems using phase data tools. To realize its time-demands, the reference station must send its phase and pseudorange data to the user in real-time using a particular data communication system.

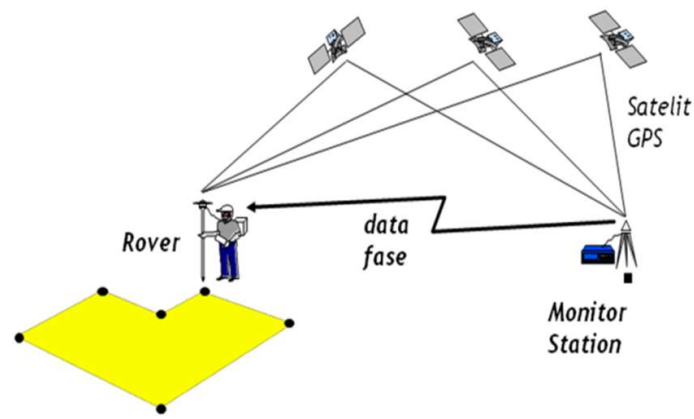

FIGURE 2. GPS Measurement of Real-Time Kinematic Method (RTK) [3]

In the Real-Time Kinematic (RTK) system, the reference station sends data to users in the RTCM format (Radio Technical Commission for Maritime Service) using a data communication system that operates on the VHF / UHF frequency band.

The typical accuracy of the position given by the Real-Time Kinematic (RTK) system is around $1-5 \mathrm{~cm}$, assuming that the ambiguity phase can be determined correctly. To determine the good phase ambiguity, two frequency phase and pseudo range data, relatively good satellite geometry, relatively reliable calculation algorithms and elimination of errors and biases are relatively good and precise. This Real-Time Kinematic (RTK) measurement requires two planes serving as reference points (Base) and positioning (Rover). Using one reference station, the Real-Time Kinematic (RTK) system can generally only be used for baseline distances to around 10-15 km. The main tools used in measuring the Real-Time Kinematic (RTK) method include the receiver base and rover, UHF radio antenna, battery, controller, tribrach, tripod, pole mount and GPS cradle, and meter. 
The depiction stage is carried out using Autodesk Land Desktop 2006. The final result expected from Real-Time Kinematic (RTK) measurement is not only in the form of coordinate and elevation data but in the form of measurement results.

Each type of Electronic Total Station (ETS) equipment will have its own characteristics in terms of usage procedures and handling data. But to study the type of ETS in general what needs to be studied are: Database Management, Specifications and Capabilities, Instrument Operating Systems [4] Leica TS 06 Total Station is an optical system measuring instrument for the needs of horizontal angles and upright angles with digital storage.

The field of land is defined as the part of the earth's surface which is a limited field unit. In measuring the land area using measuring tape for distance measurement purposes is often used, the distance obtained is then used for calculating the area. Until now most of the measurement of land parcels for the benefit of BPN and PBB is carried out terrestrial by direct measurement using measuring tape. One alternative digital mapping along with the development of mapping technology is currently Global Positioning System (GPS) technology ([5].

\section{METHODOLOGY}

\section{Research Location}

This research was conducted at the Universitas Negeri Semarang Campus. Two categories are chosen, namely;

1. An open area or not obstructed by satellite observation. The location of an open area is in front of Auditorium Building, Faculty of Sports Science.

2. Dense area or area that is obstructed by satellite observation. The location of dense area is in at the Parking Area of E1 Faculty of Engineering.

\section{Data Collecting}

The data used for analysis is obtained by means of the initial survey to determine the method of measurement, the number of measurement teams, the location of measurements and distribution of stakes for measuring land parcels. The method used is as follows;

1. Polygon measurement with Total station consisting of calculation of polygon coordinates, position of planimetric coordinates $(\mathrm{X}, \mathrm{Y})$ and accuracy, and estimation of measurements

2. GPS observation with RTK method consisting of data transmission from the reference station to the rover station, Real Time Kinematic (RTK) horizontal position from the point of polygon, coordinates (X, Y) of GPS observations and accuracy, Estimated measurement time.

\section{Data Processing}

This activity phase is preceded by calculating the average angle and distance along with the coordinates of the boundary point of the measured area. Then calculate the coordinate approach using the Bowditch method alignment. Furthermore, from this calculation, we can know the linear error of the closed polygon which is calculated and express the accuracy of the polygon.

\section{Calculation}

Polygon coordinates with the parameter method in the least squares alignment so that the error ellipse is known to later determine the dimensions and orientation of the error ellipse. In processing the results of positioning data with GPS the RTK method is performed calculations statistics to get the average price, precision measurement, and relative accuracy of GPS measurements of the RTK method. 




FIGURE 3. The Flow Chart of The Research

\section{RESULT AND DISCUSSION}

\section{Results}

The results of the measurement of the land field with the Global Positioning System (GPS) method and Total station. Discussion of the results of measurements of the land area between geodetic GPS with the total station as follows;

1. Determine the number of the team

In order for measurements to be carried out simultaneously two teams are formed, each of which is assisted by the operator and helper.

2. Determine the location of measurement and installation of stakes.

The selected measurement location is a location that is directly integrated between open locations and dense locations with 1 benchmark (BM) point. Benchmark (BM) location is located at the engineering faculty roundabout.



FIGURE 4. Location of Land Field Measurement 




FIGURE 5. Benchmark Monument (BM) at the engineering faculty roundabout

3. Measurement of Land Field at open area. Selection of measuring instruments will be compared according to the tools in the lab. Measure the land of the Department of Civil Engineering, Engineering Faculty, Universitas Negeri Semarang is also familiar to be used in the land office, the measurement data is attached.

The tools used are ;

GPS Geodetic : GPS Hemisphere S230

Total Station : TS06 Leica

Measurements carried out at once with the open location of the implementation are;

Survey 1 : GPS Hemisphere S230

Survey 2: TS06 Leica

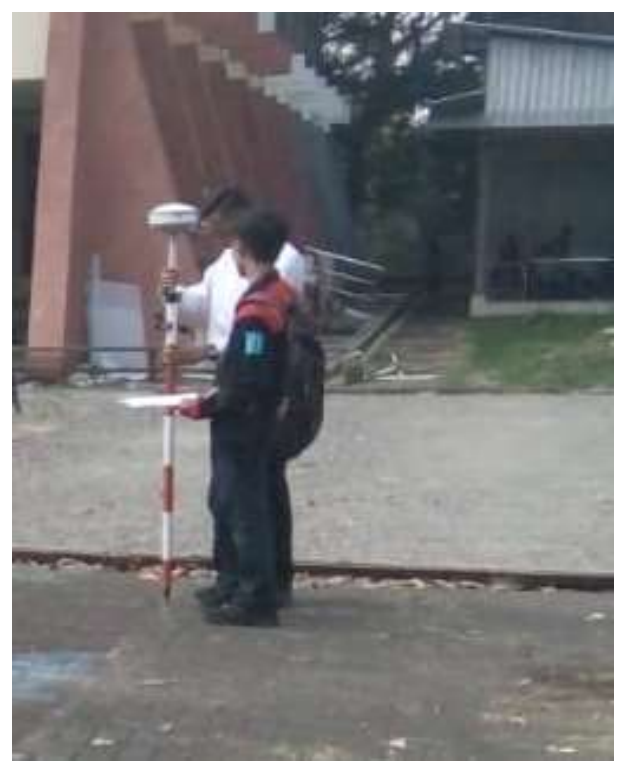

FIGURE 6. Measurement with a Geodetic GPS device in an Open Area 




FIGURE 7. Measurement with a Total Station device in an Open Area

4. Measurement of Land Field in dense area

The selected measurement location is an integrated location between open area and dense area with 1 benchmark point Mark Bench(BM) Monument is located at the Roundabout of the Faculty of Engineering, Universitas Negeri Semarang.

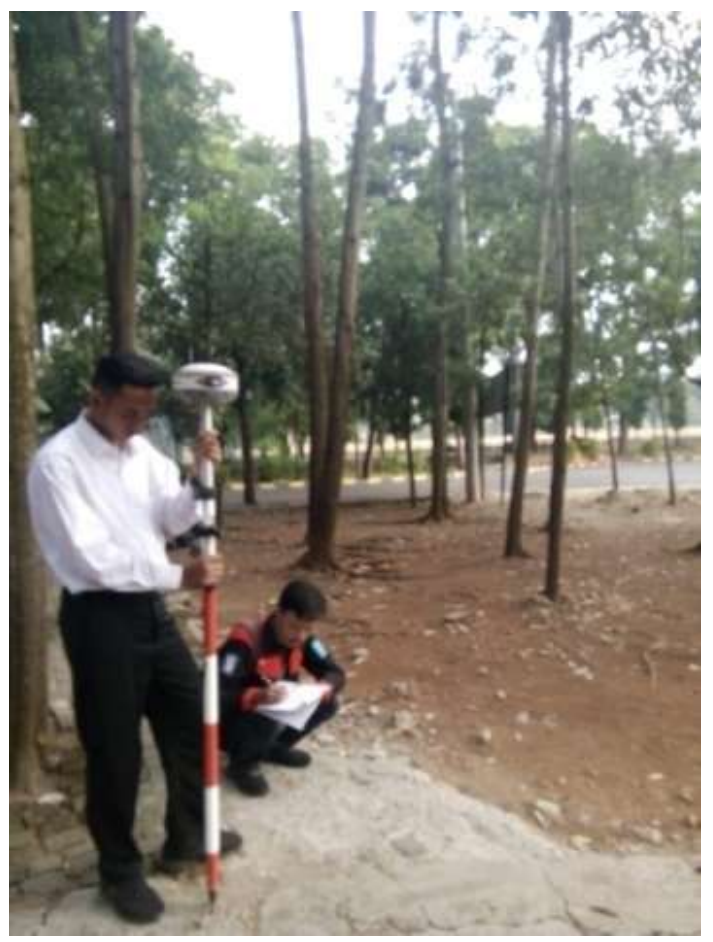

FIGURE 8. Measurement with a Geodetic GPS device in dense Area 


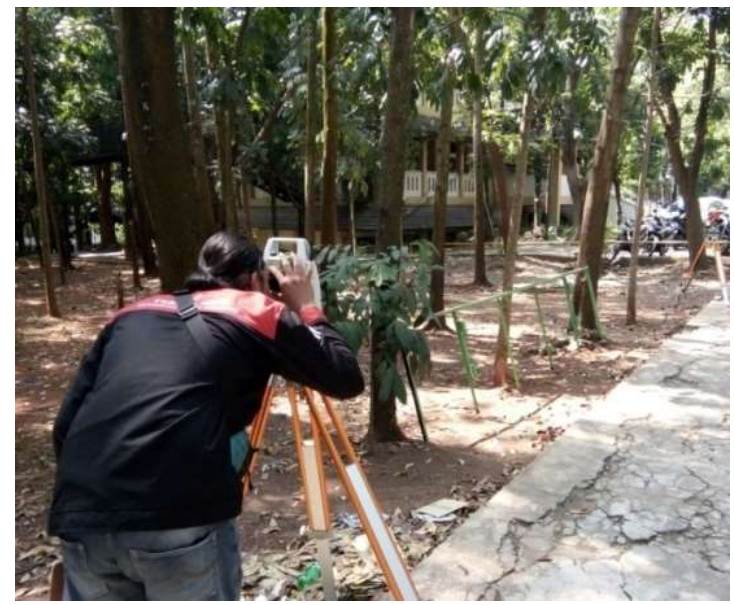

FIGURE 9. Measurement with a Total Statoon device in dense Area

5. Field Inputing Data

The measurement data in the field is taken with the software of each tool. GPS Hemsiphere with the Trimble branded Windows Mobile Manager software and data controller while the total station cable assistance with data transfer software in the menu display total station transfer to computer.

6. Depiction

For depicting the results of geodetic gps measurements and the total station, use Autocad Land Desktop. Starting from the import point - making a combined point of measurement into a plot of land (Figure 10).

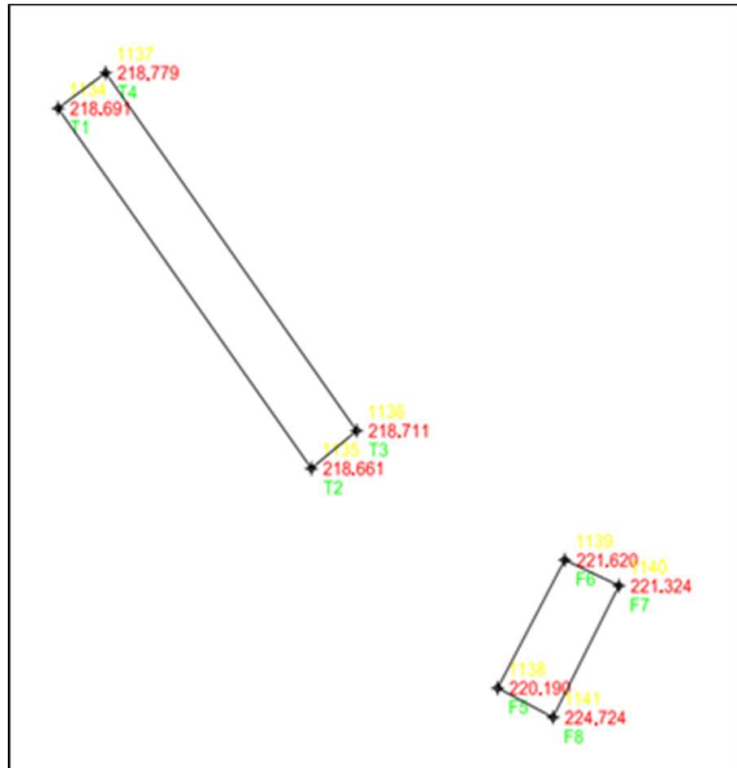

FIGURE 10. Measurement with a Total Statoon device in dense Area

\section{CONCLUSIONS AND RECOMMENDATIONS}

\section{Conclusions}

Measuring the parcel with the total station equipment in an open location with a geodetic hemisphere GPS accuracy ratio is 4 points of the measurement polygon between the Real time kinematic method and the closed polygon for 0.040 m horizontally. Geodetic GPS measurement time is two times faster than the total station with a difference of 9 
minutes 31 seconds with the Geodetic GPS retrieval status " fixed "and the total station" average ". If the assumption of a standard measurement per day is 1 ha then the time needed for 20 polygon points is 47 minutes 35 seconds.

At a closed location the comparison of the measurement accuracy between the Real time kinematic method and the closed polygon for the horizontal is $10,053 \mathrm{~m}$. the total station measurement time is two times faster than geodetic GPS with a difference of 13 minutes 46 seconds with the Geodetic GPS data retrieval status not fixed and the total station average. If the assumption of a standard measurement per day is 1 ha then the time needed for 20 polygon points is 1 hour 8 minutes 50 second.

\section{Recommendations}

In the comparative study the soil field measurement tool can then examine based on the resistance of soil measuring instruments to certain climates and terrain

\section{REFERENCES}

[1] Fajriyanto, "Studi Komparasi P emakaian GPS Metode Real Time Kinematic (RTK) Dengan Total Station (TS) Untuk Penentuan Posisi Horisontal," Rekayasa, J. Sipil dan Perenc., vol. 13, no. 2, 2009.

[2] J. Setiadi, “Aplikasi GPS RTK untuk Pemetaan Bidang Tanah,” Reka Geomatika J. Tek. Geod. dan Geomatika, vol. 1, no. 1, 2013.

[3] H. Z. Abidin, Penentuan Posisi dengan GPS dan Aplikasinya. Jakarta: PT Pradnya Paramita, 1995.

[4] B. Sasmito, TS Prinsiple. Semarang: Teknik Geodesi Universitas Diponegoro, 2011.

[5] D. B. Yuwono, Artiningsih, and Hanieeah, "Kajian Hitungan Luas Bidang Metode Stop and Go dengan Data Fase dan Precise Ephemeris Menggunakan GPS Topcon RTK HiperGb," in Prosiding Forum Ilmiah Tahunan (FIT) 2011 Ikatan Surveyor Indonesia : Optimalisasi Peran Pemerintah Daerah dan Swasta untuk Percepatan Pemetaan dan Pembangunan, 2011. 